\title{
Corrigendum: The role of drug transporters in the kidney: lessons from tenofovir
}

\author{
Darren M. Moss* \\ Department of Molecular and Clinical Pharmacology, University of Liverpool, Liverpool, UK \\ *Correspondence: darren.moss@liverpool.ac.uk
}

Edited by:

George Tegos, Massachusetts General Hospital, USA

Reviewed by:

Olaf Grisk, University of Greifswald, Germany

Keywords: tenofovir, HIV-1, drug transporters, kidney, toxicity

\section{A corrigendum on}

The role of drug transporters in the kidney lessons from tenofovir

by Moss, D. M., Neary, M., and Owen,

A. (2014). Front. Pharmacol. 5:248. doi: 10.3389/fphar.2014.00248

The authors wish to correct a mistake on the review "The role of drug transporters in the kidney: lessons from tenofovir" regarding the details of a particular ABCC2 polymorphism $[-24 \mathrm{C}>$ $\mathrm{T}$ (rs717620)]. In the Section "Tenofovir and kidney transporter pharmacogenetics" on page five of the article, the second line on the second column should state the $\mathrm{ABCC} 2$ polymorphism as $-24 \mathrm{C}>\mathrm{T}$, rather than $-24 \mathrm{~T}>\mathrm{C}$. Additionally, the sentence beginning on page five, line four of the second column should be changed from: "In a study in Japanese HIV+ patients, the $A B C C 2-24 \mathrm{C}>\mathrm{T}$ and $1249 \mathrm{G}$ $>$ A polymorphisms were found to be protective for tenofovir-induced kidney toxicity (Nishijima et al., 2012)." and instead read: "In a study in Japanese $\mathrm{HIV}+$ patients, the $A B C C 2-24 \mathrm{~T}>\mathrm{C}$ and $1249 \mathrm{G}>$ A polymorphisms were found to be associated with the increased occurrence of tenofovir-induced kidney toxicity (Nishijima et al., 2012)."

\section{REFERENCES}

Nishijima, T., Komatsu, H., Higasa, K., Takano, M., Tsuchiya, K., Hayashida, T., et al. (2012). Single nucleotide polymorphisms in ABCC2 associate with tenofovirinduced kidney tubular dysfunction in Japanese patients with HIV-1 infection: a pharmacogenetic study. Clin. Infect. Dis. 55, 1558-1567. doi: $10.1093 / \mathrm{cid} / \mathrm{cis} 772$
Conflict of Interest Statement: The author declares that the research was conducted in the absence of any commercial or financial relationships that could be construed as a potential conflict of interest.

Received: 22 December 2014; accepted: 20 January 2015; published online: 09 February 2015.

Citation: Moss DM (2015) Corrigendum: The role of drug transporters in the kidney: lessons from tenofovir. Front. Pharmacol. 6:18. doi: 10.3389/fphar.2015.00018 This article was submitted to Experimental Pharmacology and Drug Discovery, a section of the journal Frontiers in Pharmacology.

Copyright (c) 2015 Moss. This is an open-access article distributed under the terms of the Creative Commons Attribution License (CC BY). The use, distribution or reproduction in other forums is permitted, provided the original author(s) or licensor are credited and that the original publication in this journal is cited, in accordance with accepted academic practice. No use, distribution or reproduction is permitted which does not comply with these terms. 